\title{
Misdiagnosis of Bupropion Intoxication
}

\author{
Tarik Acara, d, Nurettin Onur Kutlu ${ }^{\mathrm{b}}$, Huseyin Caksen ${ }^{\mathrm{b}}$, \\ Suleyman Sahin ${ }^{\mathrm{b}}$, Mehmet Ergin ${ }^{\mathrm{c}}$, Basar Cander ${ }^{\mathrm{c}}$
}

\begin{abstract}
Bupropion inhibits catecholamine's neuronal reuptake selectively but has a minimal effect on indolamine reuptake. It can be used in the treatment of major depressive disorder. A 3.5-year-old $15 \mathrm{~kg}$ girl had vomiting and disorders in her speech. After a time, she did not take breath and stared at one point and had a seizure. She was diagnosed with epilepsy and diazepam and then phenytoin was given intravenously. Midazolam infusion was performed. Although phenytoin loading and midazolam infusion, she had seizures intermittently. Her anamnesis in terms of drug story was rechecked but her family did not give any important data. Due to atypical process in clinical picture, multi-drug survey, stomach irrigation and activated charcoal were performed. The parent found bupropion which patient's mother had used. During 14 days follow-up, she was intubated and mechanical ventilation was performed. She had resuscitation for three times due to cardiopulmonary arrest. Fortunately, after successful conservative treatment, she was discharged without any neurological sequel. Neurologic effects are tremor, pain, hallucinations, coma and seizures. Cardiovascular effects are tachycardia and widening in QRS and lengthened QT interval. Gastrointestinal effects are nausea and vomiting. Deaths were reported rarely. In our case, the patient had most of the findings stated above. So that wide QRS tachycardia firstly, then bradycardia and asystole finally had developed. When child is admitted to emergency service with seizures, their parents must be asked about intoxication.
\end{abstract}

Keywords: Bupropion; Poisoning, Complication; Convulsion; Cardiac support; Critical and intensive care

\footnotetext{
Manuscript accepted for publication May 19, 2015

${ }^{a}$ Beyhekim State Hospital, Konya, Turkey

bDepartment of Pediatrics, Meram Medical School, Necmettin Erbakan University, Konya, Turkey

${ }^{\mathrm{c}}$ Department of Emergency Medicine, Meram Medical School, Necmettin Erbakan University, Konya, Turkey

${ }^{\mathrm{d} C}$ Corresponding Author: Tarik Acar, Beyhekim State Hospital, Konya, Turkey.

Email: drtarikacar@gmail.com
}

doi: http://dx.doi.org/10.14740/jmc2180w

\section{Introduction}

Bupropion inhibits catecholamine's (noradrenalin and dopamine) neuronal reuptake selectively and also has a minimal effect on indolamine reuptake. It can be used in the treatment of major depressive disorder and is the first non-nicotine medicine approved to be used in the treatment of smoking cessation [1]. There are two forms of this medicine: fast and constant oscillation.

Convulsion incidence related to bupropion is about $0.1 \%$ $(1 / 1,000)$. It is generally expected to have sinus tachycardia, tremor and seizure on acute overdose in between 1 and $4 \mathrm{~h}$ following uptake [2]. There are a few cases reported with cardiac arrest and a case with brain death [3-7]. Generalized tonicclonic convulsions, which can result in postictal convulsions or memory disorder in some cases, are the most frequent cases. Since there are fewer side effects related to the slow oscillation form of bupropion, these forms are more preferable nowadays [8]. Also, the seizures on these forms are quite rare. In this paper, we aim to present the patients consulting to emergency services with the problem of intoxication which causes multiple seizures linked to slow oscillation form of bupropion.

\section{Case Report}

A 3.5-year-old girl, weighing $15 \mathrm{~kg}$, had started vomiting in the evening. Then she had speech disorder, after a while she had respiration difficulties and she stared at one point and had a seizure. At the initial health care facility, she was diagnosed with epilepsy and given diazepam intravenously. Since the seizure could not be stopped, phenytoin was given next. After that, the patient was transferred to our clinic for further evaluation and long-term treatment.

When the patient came, her general condition was poor, she was sleepy all the time, and had dilated pupillaries. Muscle tone was normal, DTR below $++/++$ top $++/++$, Babinski $+/+$, other systems were natural. Blood pressure 100/60 mm Hg, pulse $110 / \mathrm{min}$, temperature $36.7^{\circ} \mathrm{C}$, oxygen saturation $96 \%$, and glucose $116 \mathrm{mg} / \mathrm{dL}$ were confirmed. The patient was not in post ictal period. She was anxious and the family did not give intoxication anamnesis. Also they indicated that the patient did not go out and there was no one using regular drugs at home. Laboratory results were as follows: Hgb: 11.1, HCT: 32.2, 
WBC: 14.4, Plt: 309, Na+: $143.4 \mathrm{mmol} / \mathrm{L}$, Clor: $104 \mathrm{mmol} / \mathrm{L}$, ALT: $18 \mathrm{U} / \mathrm{L}$, AST: $30 \mathrm{U} / \mathrm{L}$, albumin: $4.3 \mathrm{~g} / \mathrm{dL}, \mathrm{Mg}: 1.97 \mathrm{mg} /$ dL, Ca: $9.91 \mathrm{mg} / \mathrm{dL}, \mathrm{K}: 4.2 \mathrm{mmol} / \mathrm{L}, \mathrm{Na}: 138 \mathrm{mmol} / \mathrm{L}$, creatinine: $0.51 \mathrm{mg} / \mathrm{dL}$, Fosfor: $4.15 \mathrm{mg} / \mathrm{dL}$, urea: $12 \mathrm{mg} / \mathrm{dL}$, Lactat: $1.77 \mathrm{mmol} / \mathrm{L}$, sedimentation: $2 \mathrm{~mm} / \mathrm{h}$, aPTT: $29.8 \mathrm{~s}$, PT (INR): 1.19, $\mathrm{PCO}_{2}: 39.2 \mathrm{~mm} \mathrm{Hg}$, Methb: 0.4\%, CoHb: 1\%, pH: 7.358, BE: -3.6 , and $\mathrm{HCO}_{3}$ act: $22.8 \mathrm{mmol} / \mathrm{L}$.

Upon the repeating seizures, she was given $10 \mathrm{mg} / \mathrm{kg}$ phenytoin IV. After loading dose of phenytoin, midazolam IV infusion was performed since her seizure had been continuing. Since she had a history of falling from height 3 week ago, computed tomography, magnetic resonance imaging (MRI) and diffusion MRI of the brain were processed, all of which were reported as normal.

During her follow-up, the general condition had been getting worse. Her pupillary was fixed and dilated. Although phenytoin loading and midazolam infusion, she had been having seizures intermittently. She was throwing her head back, and her hands were trembling. Her anamnesis in terms of drug story was rechecked but her family did not give any important data. Due to atypical process in clinical picture, multi-drug examination, stomach irrigation and activated charcoal were performed. Pediatric department agreed that her clinical picture was pointing at intoxication rather than seizure. Midazolam infusion was stopped. The patient was practiced biperiden 0.04 $\mathrm{mg} / \mathrm{kg}$ tid, since the patient's atypical movements did not stop. In the multi-drug survey, benzodiazepine was positive.

The parents were asked to search their home and bring each and every drug in their home. The parent found an opened and empty box of Welbutrin XL $150 \mathrm{mg}^{\circledR}$ which belonged to patient's mother, and she said that there should have been at least seven pills.

National Intoxication Center informed that even just one tablet of the drug was toxic and suggested intensive care for the patient. During 14 days follow-up, she was intubated and mechanical ventilation was performed. Her seizure was taken under control. However she had resuscitation for three times due to cardiopulmonary arrest. Fortunately, after successful conservative treatment, she was discharged from ICU without any neurological sequela.

\section{Discussion}

Bupropion is an antidepressant chemically unrelated with SSRI. Its chemical structure is alike to diethylpropion and amphetamine which are used in intermittent or short-term treatments of obesity. Effective mechanism of bupropion is not fully understood [9]. Since bupropion's sympatheticomimetic amine form can lead to hypothalamus stimulation and catecholamine discharge to CNS, bupropion can be responsible for the seizures in the overdose cases.

Plasma concentration of metabolites may have clinical importance because of their high level as much as bupropion or higher than bupropion. Turning of bupropion into its active metabolite form of hydroxybupropion is realized with CYP2B6 whose isoenzyme is cytochrome P450.

Reaching of hydroxybupropion to the plasma concentra- tion is realized in $7 \mathrm{~h}$. Following the intake, the highest plasma concentration of hydroxybupropion is seven times higher than the highest level of stable condition of the main drug. Hydroxybupropion's half-life is approximately about $20 \pm 5 \mathrm{~h}$.

After giving $200 \mathrm{mg}$ 14C-bupropion to the people, the radioactive dose is determined $87 \%$ in the urine and $10 \%$ in the feces. The fact that only $0.5 \%$ of bupropion is disposed from body without any changes matches the fact that this compound is comprehensively metabolized in the body [10].

It is suggested to take this drug less than $450 \mathrm{~g}$ daily [7]. The advised dose should not be exceeded in modified cyclothymic bupropion tablets. During the clinical studies, the all seizures incidents accompanied with bupropion treatment make up about $0.1 \%$. Seizures in intoxication are common in adults but rare in children [11-13]. This is generally associated with children who does not take more than 1 - 2 tablets [13]. In one case, intoxication with $1,050 \mathrm{mg}(48 \mathrm{mg} / \mathrm{kg})$ was reported [14]. In our case, the patient must have taken $1,050 \mathrm{mg}$ maximally which corresponded to $70 \mathrm{mg} / \mathrm{kg}$. In our hospital we cannot measure bupropion blood level.

Specific antidote against bupropion is not known. In acute intoxication, stomach irrigation and activated charcoal are suggested [10].

In 58 cases reported by Spiller et al, seizure rate was $21 \%$ and benzodiazepines cannot prevent seizures in its mixt overdose with bupropion. Seizures started 1 - $8 \mathrm{~h}$ later after taking [3]. Five hours later after bupropion's taking, it reaches its peak plasma and absorption continuous along 12- $15 \mathrm{~h}$ [10]. In our case we could not detect the time intake of the drug, yet the seizures did not respond to diazepam, phenytoin, midazolam as well.

Bupropion overdose mainly affects neurologic, cardiovascular and gastrointestinal system. Neurologic effects are tremor, pain, hallucinations, coma and seizures. Cardiovascular effects are tachycardia, widening in QRS and extension to the QT distance [15-17]. Gastrointestinal effects are nausea and vomiting. Deaths were reported rarely. In our case, the patient had most of the findings stated above. So that wide QRS tachycardia firstly, then bradycardia and asystole finally had developed.

Hypophosphatemia can be seen in patients [7]. In our case, from the second day till the sixth day following admission, it varied in the low level. The lowest level was $2.15 \mathrm{mg} / \mathrm{dL}$ in the third day. Hypokalemia in bupropion intoxication was reported by Spiller et al [3]. In our case, in the second day it was as low as $2.9 \mathrm{mmol} / \mathrm{L}$.

In the multi-drug test, the finding of benzodiazepine was thought to be connected to diazepam and midazolam.

In acute bupropion overdose, there can be seizures which may result by massive intake. In the status epilepticus, aggressive treatment should be applied and the patient should be admitted to ICU to monitorize cardiac dysrhythmia, acid base imbalance, electrolyte imbalance and cardiac arrest. There are positive effects of providing early and aggressive breathing support.

Our suggestion is close cardiac monitorization in bupropion overdose. Aggressive airway management is important for serious seizures in terms of resuscitation. Bradycardia, asystole may occur as a result of seizures and hypoxia in bupropion overdose cases. 
In this patient, seizures resulted in cardiac dysrhythmia, which can be fatal, depending on minimum $70 \mathrm{mg} / \mathrm{kg}$ bupropion overdose.

\section{Conclusion}

In the cases with the patients coming to the emergency service with seizures, their parents must absolutely be asked about their drug history. We should not forget the fact that some member of the family can hide their illness because of various reasons.

Bupropion, especially the active substance of the smoking cessation drug, ZYBAN, should not be left unattended and people should avoid using it with drugs that decrease the threshold of seizures.

Years ago, people used to hide their tuberculosis and that's why we could not track and check tuberculosis regularly. In this modern era, where our priority is psychological illnesses, yet there is still one thing that has not changed: mentality.

\section{References}

1. Richmond R, Zwar N. Review of bupropion for smoking cessation. Drug Alcohol Rev. 2003;22(2):203-220.

2. Rumack BH, Ekins BR. Bupropion therapeuticltoxic class. In: Poisindex Information System. Rumack BH, ed. Denver: Micromedex Inc, Edition expires 11/30/95.

3. Spiller HA, Ramoska EA, Krenzelok EP, Sheen SR, Borys DJ, Villalobos D, Muir S, et al. Bupropion overdose: a 3-year multi-center retrospective analysis. Am J Emerg Med. 1994;12(1):43-45.

4. Friel PN, Logan BK, Fligner CL. Three fatal drug overdoses involving bupropion. J Anal Toxicol. 1993;17(7):436438.

5. Rohrig TP, Ray NG. Tissue distribution of bupropion in a fatal overdose. J Anal Toxicol. 1992;16(5):343-345.

6. Ramcharitar V, Levine BS, Goldberger BA, Caplan YH. Bupropion and alcohol fatal intoxication: case report. Forensic Sci Int. 1992;56(2):151-156.

7. Harris CR, Gualtieri J, Stark G. Fatal bupropion overdose. J Toxicol Clin Toxicol. 1997;35(3):321-324.

8. Rissmiller DJ, Campo T. Extended-release bupropion induced grand mal seizures. J Am Osteopath Assoc. 2007; 107(10):441-442.

9. Gobbi G, Slater S, Boucher N, Debonnel G, Blier P. Neurochemical and psychotropic effects of bupropion in healthy male subjects. J Clin Psychopharmacol. 2003;23(3):233-239.

10. Wellbutrin XL. [package insert]. Research Triangle Park, NC: Glaxo Smith Kline. 2006.

11. Spiller HA, Bosse GM, Beuhler M, Gray T, Baker SD. Unintentional ingestion of bupropion in children. J Emerg Med. 2010;38(3):332-336.

12. Shepherd G, Velez LI, James DK. Pediatric bupropion exposures reported in Texas: 1998-1999. J Toxicol Clin Toxicol. 2001;39:263.

13. Belson MG, Kelley TR. Bupropion exposures: clinical manifestations and medical outcome. J Emerg Med. 2002;23(3):223-230.

14. Spiller HA, Schaeffer SE. Multiple seizures after bupropion overdose in a small child. Pediatr Emerg Care. 2008;24(7):474-475.

15. Curry SC, Kashani JS, LoVecchio F, Holubek W. Intraventricular conduction delay after bupropion overdose. J Emerg Med. 2005;29(3):299-305.

16. Shrier M, Diaz JE, Tsarouhas N. Cardiotoxicity associated with bupropion overdose. Ann Emerg Med. 2000;35(1):100.

17. Biswas AK, Zabrocki LA, Mayes KL, Morris-Kukoski CL. Cardiotoxicity associated with intentional ziprasidone and bupropion overdose. J Toxicol Clin Toxicol. 2003;41(1):79-82. 